\title{
The Impact of Tertiary EFL Teachers' Professional Identity on Job Burnout in Hubei Province China
}

-Jing Zhao: College of Foreign Language Studies, Hubei Normal University, 435002 Hubei Province, China Faculty of Business, Information and Human Sciences, Infrastructure University Kuala Lumpur (IUKL), 43000 Selangor, Malaysia.

Siti Maziha Mustapha: Faculty of Business, Information and Human Sciences, Infrastructure University Kuala Lumpur (IUKL), 43000 Selangor Malaysia.

Jun Wang: College of Foreign Language Studies, Hubei Normal University, 435002 Hubei Province, China.

\begin{abstract}
In order to explore the relationships of tertiary EFL teachers' professional identity and job burnout, a quantitative survey was conducted on 565 tertiary EFL teachers in Hubei Province in central China. The results indicated that teachers with different educational background and teachers teaching different types of students experience different levels of burnout; Tertiary EFL teachers' professional identity were significantly negatively related to their job burnout; The valence and self-presentation in professional identity can be used to predict teachers' job burnout. Therefore, tertiary EFL teachers should try to enhance their occupational belongings so as to alleviate their current job burnout and promote their sustainable development.
\end{abstract}

Key words: Tertiary EFL teachers, Professional identity, Job burnout

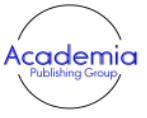

International Journal of Educational Studies

Vol. 3, No.3, pp. 97-105

2020

DOI: $10.53935 / 2641-533 x . v 3 i 3.145$

Corresponding Author: Jing Zhao

Funding: This article is supported by Teaching Reform Project $606 f$ Hubei Normal University: Reform Project 6o6f Hube Normal University: The Construction of U-S Synergistic Learning Community to Promote the Professional Development of Primary and Secondary School
Teachers (Project No: Teachers (Project No:

2019056), and funds for Industry-University Cooperation and Education project of the Ministry of Education (Project No:

201901297002.

Article History:

Received: 21 July 2020

Revised: 26 August 2020

Accepted: 16 September 2020

Published: 19 October 2020

(C) 2020 by the authors; licensee Academic

Publishing Group

\section{Introduction}

After entering the $21^{\text {st }}$ century, college English teaching in China has experienced large-scale curriculum reform. The implementation of National Criteria of Teaching Quality for Undergraduate English Majors and Guidelines on College English Teaching provided a vision for EFL (English as a Foreign Language) teaching reform and prescribed a series of standards for English teaching curriculum. English teaching in colleges and universities in China is experiencing a trend to transform teaching English for general purpose to teaching English for specific purpose as well as for academic purpose. Under such background, tertiary EFL teachers, as the main force of the implementation of English teaching, face great pressure, which might lead to job burnout in their development.

Besides that, there also exist a great imbalance in tertiary EFL teachers' gender, professional title, education background (Wang \& Wang, 2011) and they are often marginalized under current assessment mechanism in colleges and universities (Wang, 2016) compared with teachers teaching other subjects. Therefore the understanding of the inner world of tertiary EFL teachers, especially their professional identity, has become a major way to promote their career development, which is also of great importance to improve foreign language teaching in colleges and universities in China. Parker (1998) believed that the essence of teaching was not the application of a specific teaching method, but the extent to which teachers 


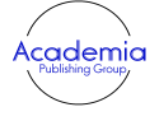

International Journal of Educational Studies

Vol. 3, No.3, pp. 97-105

2020

DOI: 10.53935/2641-533x.v3i3.145

Corresponding Author: Jing Zhao

Funding: This article is supported by Teaching Reform Project $606 f$ Hubei Normal University: The Construction of U-S Synergistic Learning The Construction of U-S Synergistic Learning
Community to Promote the Professional Community to Promote the Professional Development of Prim

Teachers (Project No:
2019056), and funds for Industry-University Cooperation and Education project of the Ministry of Education (Project No:

201901297002.

Article History:

Received: 21 July 2020

Revised: 26 August 2020

Accepted: 16 September 2020

Published: 19 October 2020

(C) 2020 by the authors; licensee Academic

Publishing Group integrated their identity into teaching. From this point of view, teachers' professional identity would certainly affect their job burnout. Teachers with low professional identity are more likely to suffer job burnout (Hu, 2016; Zhang, 2019). In recent years, the phenomenon of job burnout among tertiary EFL teachers has attracted researchers' increasing attention, and some found that teacher professional identity determines the attitude of teachers' work behavior, which deeply affects the level of teachers' job burnout.

This paper would review the researches on the relationship of tertiary EFL teachers' professional identity and job burnout in order to further clarify the internal mechanisms and gain an in-depth understanding of the characteristics of tertiary EFL teachers' professional identity and job burnout in Hubei Province in China, and then provide some useful enlightenment to alleviate their job burnout and promote their professional development.

\section{Literature Review}

\subsection{Teacher Professional Identity}

In China, the research on EFL teachers' education and development has just started, which mainly focus on teachers' mastery of the language and linguistic theory, neglecting their inner world. Wu (2008) pointed out that the essence of EFL teachers' development lies in the development of their professional identity. Therefore studies of EFL teachers' professional identity from the perspective of sociology, philosophy and linguistics provide a new research direction in the field of foreign language teacher development.

Teachers' professional identity is a process in which an individual gradually develops from his own experience and confirms his role as a teacher, which can be also regarded as the degree to which an individual teacher identifies with the career he is engaged in Wei (2005). Researchers believed that teachers' identity in their career would affect their efficiency of work, career development and their ability and willingness to perform education reform in the teaching practice (Beijaard, Verloop, \& Vermunt, 2000). As for teachers, how to develop their professional identity and their understanding of their professional identity is of vital importance on their career development.

Many theoretical studies on teacher professional identity have been found in literature, but only few authors clearly state the definition in their research. Lim (2011) proposed that "professional identity formation involves a continuous process of identification, interpretation, reinterpretation and negotiation of self-images, teaching and learning experiences, and professional roles associated with a certain sociocultural and institutional context. This process involves struggles and tensions which are a result of the integration of the different perspectives, expectations and professional roles". Martínez-de-la-Hidalga and VillardónGallego (2016) believed that "there is not a consensual definition of professional identity. Usually, it refers to the way teachers see themselves professionally as a result of how they interpret the continuous interactions that occur in professional contexts. It is shaped by the interactions that are established between personal, professional and situational dimensions".

Chinese Scholar Wei (2005) is an expert in teacher professional identity, early in her master's dissertation, she proposed that professional identity is a process in which individuals establish their professional roles according to their own experiences, which can be regarded as their degree of recognition of their own occupation. Furthermore, she designed a questionnaire to measure primary and secondary school teachers' professional identity by deconstructing it into six dimensions: cognition, will, emotion, expectation, skills and values.

Considering the definitions mentioned above, it can be seen that teachers' professional identity is clearly associated with the interactions that occur in a professional context. Along with further studies of professional identity in the group of teachers, domestic scholars also gradually deepen their research in this field. Quantitative researches are mainly carried out in China, and the content of the research is mainly embodied in the analysis of the current situation of teachers' professional identity and its correlations with other variables.

\subsection{Teacher Job Burnout}

As early as the mid-1970s, American psychologist Freudenberger began his exploration of job burnout. He transplanted the concept of job burnout from psychology to the field of education, which caused a research upsurge of teacher job burnout. Maslach, Schaufeli, and Leiter (2001) takes a closer look at job burnout, who described burnout as a chronic response caused by an individual's inability to effectively cope 


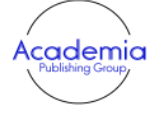

International Journal of Educational Studies

Vol. 3, No.3, pp. 97-105

2020

DOI: $10.53935 / 2641-533 x . v 3 i 3.145$

*orresponding Author: Jing Zhao

Funding: This article is supported by Teaching Funding: This article is supported by Teaching Reform Project 6o6f Hubei Normal University: The Construction of U-S Synergistic Learning Community to Promote the Professional Development of Primary and Secondary School
Teachers (Project No:

2019056), and funds for Industry-University Cooperation and Education project of the Ministry of Education (Project No.

201901297002).

Article History:

Received: 21 July 2020

Revised: 26 August 2020

Accepted: 16 September 2020

Published: 19 October 2020

(C) 2020 by the authors; licensee Academic

Publishing Group with constant stress at work. She further divided job burnout into emotional exhaustion, depersonalization and reduced personal accomplishment. To be specific, the state of emotional exhaustion is usually caused by stress at work; depersonalization refers to such problems as weak interpersonal relationships, lack of closeness to others, or decreased interest in work; Reduced personal accomplishment includes a lack of success experience in work, lack of motivation, or lack of self-confidence.

It is widely recognized that job burnout influences the teacher's moral behavior, and hinders achievement of education goals. A burned-out teacher affects school culture and may even affect his or her colleagues' work satisfaction (Friedman \& Gavish, 2003). In the 1980s, teachers' job burnout gradually attracted researchers' attention and became one of the research directions in the field of teacher education in the following three decades. Many researchers have pointed out that the profession of teachers has its own particularity, and it is more stressful compared with other professions.

Chinese scholars (Yang \& Yang, 2002) made a deep analysis on teachers' job burnout, and they insisted that teachers' job burnout would have a great negative impact on their physical and mental health, on their career development, and even on the whole education system and society studied the impact of teacher burnout on education, and he concluded that teachers' job burnout would directly affect their educational and teaching ability, who had a poor relationship with their students, which would certainly affect students' learning efficiency in class.

As can be seen from previous literature that teacher job burnout is common among teachers in China, and it has a negative impact on teachers' career, professional development, work status and physical and mental health to a certain degree. Empirical studies about teachers' job burnout may also lead to different results due to different regions, genders, professional titles and so on.

\subsection{Studies on the Relationship of Teacher Professional Identity and Teacher Job Burnout}

As for studies on the correlations of teachers' professional identity and job burnout, found out that there was a significant negative relationship between teachers' professional identity and job burnout, that is, when teachers have high sense of professional identity, their burnout level is relatively low. In the sense teachers' burnout level can be predicted by their professional identity to some extent. Therefore, improving teachers' professional identity, such as providing more material and spiritual support, can promote their love for work, stimulate their working enthusiasm and reduce their sense of burnout.

Ye and Sun (2014) concluded in their research that teachers of different ages and different years of teaching had significant differences in their overall level of job burnout, especially in the dimension of emotional exhaustion, and they further confirmed that teacher professional identity can predict job burnout. $\mathrm{Xu}$, Yang, Zhang, and Zhou (2015) analyzed the generation of PE teachers' professional emotion from the psychology, which followed the process of "feeling- cognition-experience-reaction". Finally, they put forward some strategies to convert PE teachers' job burnout to professional identity. First, school administrators should pay attention to the assessment of pre-service PE teachers' professional quality as well as to the cultivation of professional emotion. Second, a good working environment and favourable academic research atmosphere should be created to stimulate the enthusiasm and motivation of PE teachers. Thirdly, extensive emotional communication activities can be carried out to correctly guide and care for their emotional world. Finally, specific and feasible rewards and punishments policies should be formulated for PE teachers.

Although existing studies have proved that there is a significant correlation between teachers' professional identity and job burnout, studies targeting at Chinese tertiary EFL teachers are rare. Furthermore, earlier studies mainly focus on theoretical analysis, but lack of long-term follow-up empirical study or action research. Last but not least, previous studies look at the variable of teacher professional identity as one simple dimension, but in fact it can also be divided into many sub-dimensions, and different dimensions do not have equal impact to predict job burnout. Therefore this research attempts to contribute to previous literature by providing a more though investigation of the relationships of tertiary EFL teachers' professional identity and their job burnout.

\subsection{Research Questions}

With an attention to tertiary EFL teachers' professional identity and job burnout, the following research questions were explored in this study:

1. What are tertiary EFL teachers' perceptions of their professional identity and job burnout? 
2. Is there a significant relationship between tertiary EFL teachers' professional identity and job burnout ?

3. Which dimension of tertiary EFL teachers' professional identity contributes most to their job burnout?

\section{Method Sample}

According to the statistics of Ministry of Education, there are altogether 129 higher colleges and universities in Hubei Province. First stratified sampling is used to divide all these 129 universities into four different clusters according to different categories (Comprehensive University, Normal University, University of Science and Engineering and University of Finance and Economics), and then cluster sampling is employed to select twelve universities from each group. Online questionnaires were distributed to EFL teachers in these 12 universities. A total of 600 questionnaires were issued and 565 were recovered, with a recovery rate of $94.16 \%$.

Table 1 shows the general information of the participants. It can be seen that the number of female teachers far exceed that of male teachers. Teachers aged between 31 and 40 account for the largest group $(59.5 \%)$, and the majority has 11 to 15 years of teaching. It can be also found that most tertiary EFL teachers have got a master's degree $(64.4 \%)$, but only $6.4 \%$ of them possess a doctorate degree. Teachers with a professional title of lecture occupy the largest group, while only $4.8 \%$ has got the title of professor. There is not much difference in the majors of their students.

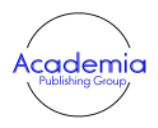

International Journal of Educational Studies

Vol. 3, No.3, pp. 97-105

2020

DOI: 10.53935/2641-533x.v3i3.145

Corresponding Author: Jing Zhao

Funding: This article is supported by Teaching Runding: This article is supported by Teaching Reform Project 6o6f Hubei Normal University: The Construction of U-S Synergistic Learning
Community to Promote the Professional Community to Promote the Professional Development of Primary
Teachers (Project No:

Teachers (Project No: Cooperation and Education project of the Ministry of Education (Project No:

201901297002).

Article History:

Received: 21 July 2020

Revised: 26 August 2020

Accepted: 16 September 2020

Published: 19 October 2020

(C) 2020 by the authors; licensee Academic

Publishing Group
Table-1. Overview of the Participants.

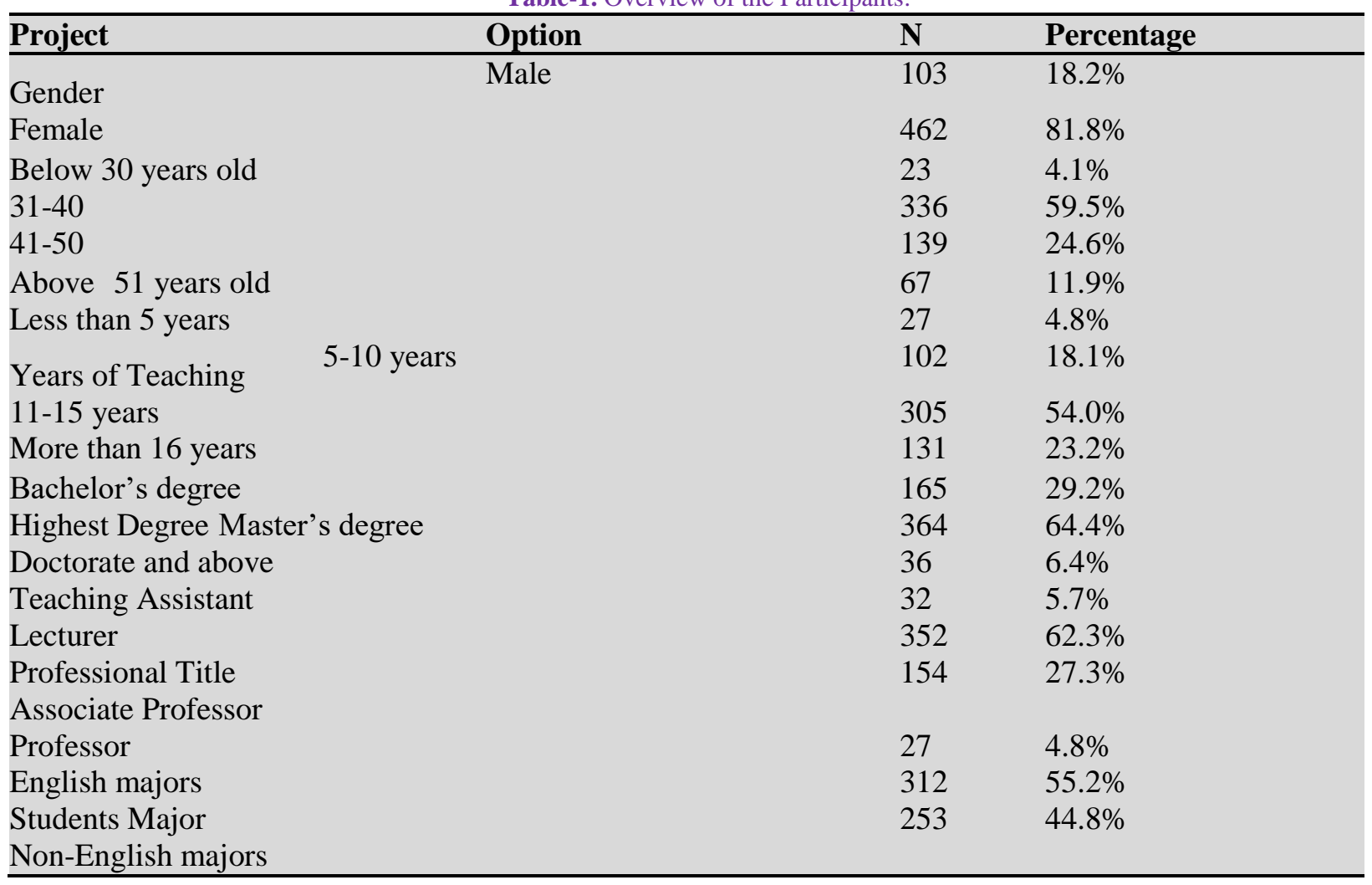

\subsection{Instruments}

After the screening and cleaning of the original data, confirmatory factor analysis was used to test the validity of the instruments, whose results showed that the validity of the two questionnaires were good. The Average Variance Extracted (AVE) for teacher professional identity was 0.541 and the Composite Reliability (CR) was 0.825. While the AVE for teacher job burnout was 0.584 and the CR was 0.808 . The values of AVE all surpass the threshold of 0.5 , and the CR values for the constructs and sub- constructs all exceed the limit of 0.6 (Hair, Sarstedt, Matthews, \& Ringle, 2016) (See Table 2 below). 


\begin{tabular}{lll}
\hline Construct & $\begin{array}{l}\text { AVE } \\
\text { (above 0.5) }\end{array}$ & $\begin{array}{l}\text { CR } \\
\text { (above 0.6) }\end{array}$ \\
\hline Teacher Professional Identity & 0.541 & 0.825 \\
Teacher Job Burnout & 0.584 & 0.808 \\
\hline
\end{tabular}

\subsection{Teacher Professional Identity Scale}

Kremer and Hofman (1985) questionnaire of "Professional Identity Scale (PRIS)" was adapted to measure tertiary EFL teachers' professional identity. This questionnaire used a five-point Likert Scale with 1 refers to strongly disagree and 5 refers to strongly agree. On the basis of the testing of Exploratory Factor Analysis (EFA) and Confirmatory Factor Analysis (CFA) in a pilot study, 16 of the original 17 questions were left to perform the real study. There were four sub-dimensions in this questionnaire, namely valence, centrality, solidarity and self-presentation. The Cronbach's $\alpha$ is 0.927 , indicating that the reliability of the scale is good (see Table 3).

Table-3. The Reliability of Teacher Professional Identity.

\begin{tabular}{ll}
\hline Cronbach's Alpha & N of Items \\
\hline 0.927 & 16 \\
\hline
\end{tabular}

\subsection{Job Burnout Inventory - Educator Survey}

The most widely used Maslach Burnout Inventory-Educator Survey was employed to evaluate tertiary EFL teachers' job burnout. This burnout inventory used a seven-point Likert Scale, with 0 meaning never and 6 meaning every day. In the pilot study, Exploratory Factor Analysis (EFA) and Confirmatory Factor Analysis (CFA) were tested, and 21 of the original 22 questions were left to perform the real study. Those 21 Questions have been further divided into three dimensions: emotional exhaustion, depersonalization and reduced sense of achievement. Emotional exhaustion refers to the excessive consumption of individuals' emotional resources, which lead to the decrease of their enthusiasm for the work they are engaged in. Depersonalization refers to the cold and distant attitude towards their students, which result in gradual reluctance to interact with others. Reduced sense of achievement is the lack of sense of success in work and the sense of achievement from work reduced, often feel their work lack of progress, or even reduced. Table 4 shows the Cronbach's $\alpha(r=0.947)$, indicating that it reliability is good.

Table-4. The Reliability of Teacher Job Burnout.

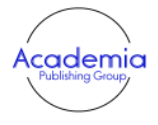

International Journal of Educational Studies

Vol. 3, No.3, pp. 97-105

2020

DOI: 10.53935/2641-533x.v3i3.145

Corresponding Author: Jing Zhao

Funding: This article is supported by Teaching Reform Project 6o6f Hubei Normal University: The Construction of U-S Synergistic Learning The Construction of U-S Synergistic Learning
Community to Promote the Professional Community to Promote the Professional Development of Primary and Secondary School
Teachers (Project No:

2019056), and funds for Industry-University Cooperation and Education project of the Ministry of Education (Project No.

201901297002).

Article History:

Received: 21 July 2020

Revised: 26 August 2020

Accepted: 16 September 2020

Published: 19 October 2020

(c) 2020 by the authors; licensee Academic

Publishing Group

\begin{tabular}{ll}
\hline Cronbach's Alpha & N of Items \\
\hline 0.947 & 21 \\
\hline
\end{tabular}

\section{Results}

To determine whether there was a significant relationship between teacher professional identity and job burnout, software SPSS25.0 was used to process descriptive statistics, correlation analysis and regression analysis. First, descriptive analysis was adopted to show the general description of the main variables. Secondly, correlation analysis was conducted to explore the relationship of teacher professional identity and job burnout. Finally, regression analysis was utilized to prove which dimension of tertiary EFL teachers' professional identity contributes most to their job burnout.

\subsection{Descriptive Statistics of the Variables}

The descriptive statistics of all sub-dimensions of tertiary EFL teachers' professional identity and job burnout are shown in table

5. The overall average score of professional identity was 3.65 , and the standard deviation 0.789 , which means that EFL teachers' professional identity is not very high. 


\begin{tabular}{llllll}
\multicolumn{7}{c}{ Table-5. Descriptive Statistics of the Variables. } \\
\hline Descriptive Statistics & $\mathbf{N}$ & Minimum & Maximum & Mean & Std. Deviation \\
\hline Teacher Professional Identity & 565 & 1.56 & 5.00 & 3.65 & .789 \\
Teacher Job Burnout & 565 & 1.28 & 7.00 & 3.69 & 1.186 \\
\hline
\end{tabular}

Of all the four dimensions, the value of self-presentation $>$ solidarity $>$ centrality $>$ valence. The mean of job burnout was 3.69, and the standard deviation 1.186, which is a little higher than medium. Of all the three dimensions, the value of emotional exhaustion is the highest, while the value of personal accomplishment is the lowest.

Table-6. Descriptive Statistics of the Sub - Constructs.

\begin{tabular}{llll}
\hline Variable & Sub - Constructs & Mean & SD \\
\hline \multirow{2}{*}{$\begin{array}{lll}\text { Teacher } \\
\text { Professio }\end{array}$} & Valence & 3.59 & 0.964 \\
nal & Centrality & 3.67 & 1.066 \\
Identity & Solidarity & 3.69 & 0.952 \\
& & & \\
& & 3.74 & 0.955 \\
Teacher & Self-Presentation & 3.73 & 1.423 \\
Job & Emotional Exhaustion & 3.67 & 1.355 \\
Burno & Depersonalization & & 1.443 \\
ut & Personal Accomplishment & 3.62 & \\
\hline
\end{tabular}

Table-7. Descriptive Statistics of Teacher Professional Identity.

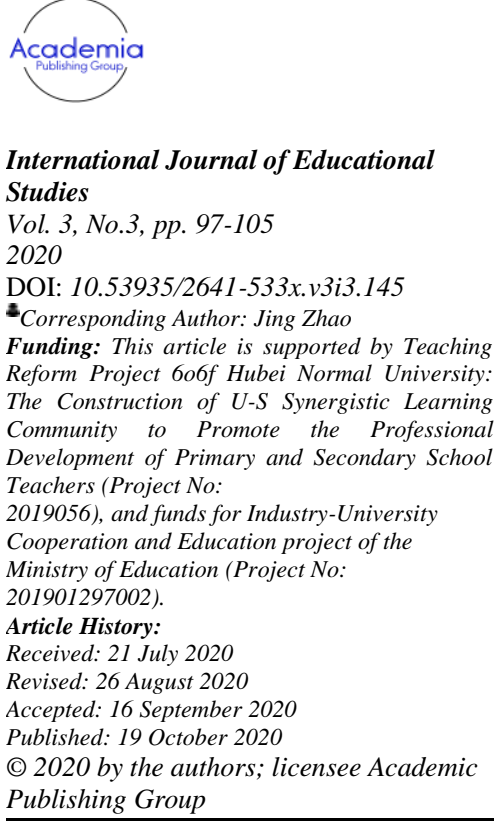

\begin{tabular}{llllll}
\hline & $\mathbf{N}$ & Mean & Deviation & t & p \\
\hline Female & 103 & 3.606 & 0.867 & -0.640 & 0.522 \\
Gender & 462 & 3.661 & 0.771 & & \\
Male & & & & & \\
below 30 & 23 & 3.973 & 0.437 & 2.382 & 0.069 \\
$31-40$ & 336 & 3.638 & 0.780 & & \\
Age & 139 & 3.569 & 0.838 & & \\
41-50 & & & & & \\
upon 51 & 67 & 3.776 & 0.796 & & \multirow{2}{*}{0.038} \\
Less than 5 years & 27 & 3.796 & 0.608 & & \\
5-10 years & 102 & 3.808 & 0.699 & & \\
Years of Teaching & 305 & 3.570 & 0.807 & & \\
11-15 years & & & & & \\
16-20 years & 131 & 3.688 & 0.826 & & \\
Bachelor & 165 & 3.663 & 0.752 & 3.324 & 0.037 \\
Highest Degree Master & 364 & 3.615 & 0.810 & & \\
Doctorate & 36 & 3.967 & 0.678 & & \\
Teaching Assistant & 32 & 3.865 & 0.606 & 1.937 & 0.122 \\
Lecturer & 352 & 3.598 & 0.793 & & \\
Professional Title & 154 & 3.735 & 0.808 & & \\
Associate Professor & & & & & \\
Professor & 27 & 3.613 & 0.771 & & \\
English majors & 312 & 3.616 & 0.779 & -1.166 & 0.244 \\
Student Major & 253 & 3.694 & 0.801 & & \\
Non-English majors & & & & & \\
\hline
\end{tabular}


Independent-Samples T-Test and ANOVA were performed to determine whether there were significant differences between different groups of teachers in relation to their professional identity and job burnout.

Table 7 shows that tertiary EFL teachers' professional identity has no significant differences in their gender, age, professional title and student type, since the p-values higher than 0.05 , while there were significant differences between in the years of teaching and teachers' highest degree. It can be seen that teachers who have working for 5 to 10 years have higher sense if identity that those who have worked for 11 to 15 years, and teachers with a doctorate degree tends to have much high professional identity then teachers with a master degree.

According to Table 8, no significant differences were found in tertiary EFL teachers' job burnout regarding their gender, age, years of teaching or professional title since the p-values are higher than 0.05 , but significant differences were found in their highest degree and student type. Teachers with a master degree were more burned out than teachers with a doctorate degree. Regarding student type, teachers teaching nonEnglish majors tended to suffer job burnout than those teaching English major students.

\begin{tabular}{|c|c|c|c|c|c|c|}
\hline Category & Items & $\mathbf{N}$ & Mean & $\begin{array}{l}\text { Std. } \\
\text { Deviation }\end{array}$ & $\mathbf{t}$ & p \\
\hline \multirow{3}{*}{ Gender } & Female & 103 & 3.789 & 1.191 & \multirow[t]{2}{*}{0.980} & \multirow[t]{2}{*}{0.328} \\
\hline & Male & 462 & 3.662 & 1.185 & & \\
\hline & below 30 & 23 & 3.870 & 1.096 & \multirow[t]{4}{*}{0.642} & \multirow[t]{4}{*}{0.588} \\
\hline \multirow[t]{4}{*}{ Age } & $31-40$ & 336 & 3.720 & 1.167 & & \\
\hline & $41-50$ & 139 & 3.634 & 1.290 & & \\
\hline & upon 51 & 67 & 3.553 & 1.086 & & \\
\hline & Less than 5 years & 27 & 3.749 & 1.100 & \multirow[t]{4}{*}{1.982} & \multirow[t]{4}{*}{0.116} \\
\hline \multirow[t]{3}{*}{ Years of Teaching } & $5-10$ years & 102 & 3.779 & 1.258 & & \\
\hline & $11-15$ years & 305 & 3.742 & 1.200 & & \\
\hline & $16-20$ years & 131 & 3.466 & 1.094 & & \\
\hline \multirow{3}{*}{ Highest Degree } & Bachelor & 165 & 3.533 & 1.150 & \multirow[t]{3}{*}{4.091} & \multirow[t]{3}{*}{0.017} \\
\hline & Master & 364 & 3.786 & 1.189 & & \\
\hline & Doctorate & 36 & 3.360 & 1.210 & & \\
\hline \multirow{4}{*}{ Professional Title } & Teaching Assistant & 32 & 3.854 & 0.923 & \multirow[t]{4}{*}{0.662} & \multirow[t]{4}{*}{0.576} \\
\hline & Lecturer & 352 & 3.681 & 1.181 & & \\
\hline & Associate Professor & 154 & 3.622 & 1.215 & & \\
\hline & Professor & 27 & 3.901 & 1.370 & & \\
\hline \multirow[t]{2}{*}{ Students Major } & English majors & 312 & 3.491 & 1.128 & \multirow[t]{2}{*}{-4.354} & \multirow[t]{2}{*}{0.000} \\
\hline & Non-English majors & 253 & 3.924 & 1.213 & & \\
\hline
\end{tabular}

\subsection{Correlation of Tertiary EFL Teachers' Professional Identity and Job Burnout}

It has been found that there was a significant negative correlation between tertiary EFL teachers' professional identity and job burnout, with a correlation coefficient of -0.251 . 
Table-9. The Causal Effects of Teacher Professional Identity on Teacher Job Burnout.

\begin{tabular}{lllllllll} 
Construct & & Path & Construct & Estimate & S.E. & C.R. & P & Result \\
\hline $\begin{array}{l}\text { Teacher } \\
\text { Burnout }\end{array}$ & Job & & Teacher & & & & & \\
& & $<---$ & Professional Identity & -.251 & .086 & -2.911 & .004 & Significant
\end{tabular}

In the dimension of valence identity, the partial regression coefficient $\mathrm{P}$ is $-0.21, \mathrm{P}<0.05$, which has a significant regression relationship with job burnout. The influence of ability identity on job burnout is negative, that is, the stronger EFL teachers' valence is, the lower the degree of job burnout will be. Similarly, the dimension of self-presentation in identity has a significant regression relationship with job burnout, with the partial regression coefficient $\mathrm{P}$ is $-0.137, \mathrm{P}<0.05$. The influence of self- presentation on job burnout is negative, that is, the stronger the self-presentation of EFL teachers, the lower the degree of job burnout.

Table-10. Coefficients ${ }^{\mathrm{a}}$ of Sub-Constructs of Teacher Profession Identity and Job Burnout

\begin{tabular}{llllll}
\hline \multicolumn{2}{l}{$\begin{array}{l}\text { Unstandardized Coefficients } \\
\text { Model }\end{array}$} & B & Std. Error & \multicolumn{3}{l}{$\begin{array}{l}\text { Standardized } \\
\text { Coefficients } \\
\text { Beta }\end{array}$} & t & Sig. \\
\hline (Constant) & 5.260 & .239 & & 22.012 & .000 \\
Valence & -.210 & .062 & -.170 & -3.386 & .001 \\
Centrality & -.079 & .057 & -.071 & -1.396 & .163 \\
Solidarity & -.005 & .064 & -.004 & -.083 & .934 \\
Self-Presentation & -.137 & .059 & -.111 & -2.315 & .021 \\
\hline
\end{tabular}

Note: a. Dependent Variable: Teacher Job Burnout

\section{Discussions}

\subsection{Tertiart EFL Teachers' Professional Identity and Job Burnout Level}

Tertiary EFL teachers' professional identity in Hubei Province in China is at a medium level, among which, the solidarity is the highest, meaning that the company of their colleagues provide teachers with a sense of belonging. At the same time it can also be inferred that EFL teachers in Hubei Province can correctly and clearly understand their profession as college teachers and have high expectations for their career development.

Analysis of tertiary EFL teachers' demographic information shows that job burnout does exist, but it is not particularly serious. However, tertiary EFL teachers' personal accomplishment is relatively low, which is greatly related to their valence, namely their love for being a teacher. At present, the society has diversified assessment criteria to evaluate the success of college students, and many students do not recognize the efforts of their teachers when they succeed in the society, resulting in a low sense of achievement of teachers. EFL teachers with different educational background have different burnout level. Teacher with a doctorate degree seem to suffer less from job burnout. Maybe richer learning experience enables them to have deeper theoretical knowledge and broader vision about teaching, and they are more willing to apply what they have learned into practice. Meanwhile, combined with the type of students they teach, it seems that teachers teaching English major students have more sense of accomplishments.

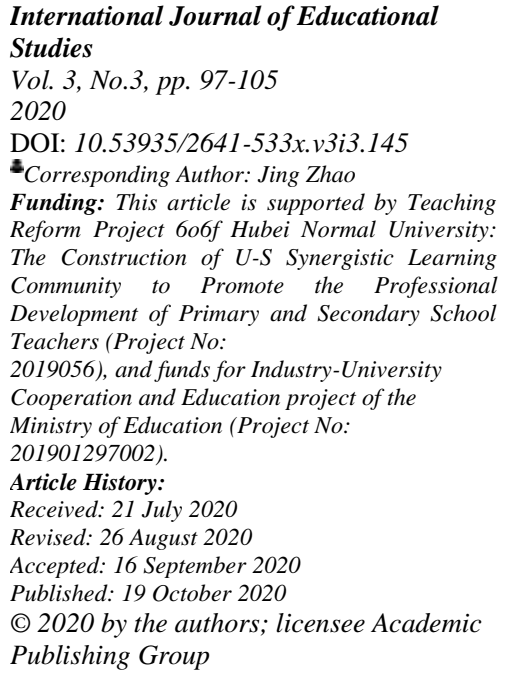

\subsection{Relationship between EFL Teachers' Professional Identity and Job Burnout}

The findings of this study support previous literature in the sense that teacher professional identity are important factors predicting teacher job burnout. Teachers' professional identity and job burnout are significantly negatively correlated. To be specific, when a teacher has the feeling that teaching is attractive, and finds out the value in teaching, he or she is less likely to feel bored in work.

Besides that, this study also enriches previous literature with the finding that the valence and self presentation can be used to predict the job burnout. If teachers have more recognition in these two aspects, they are more likely to take pride in their career. No matter how tired they feel at work, they are not prone to suffer job burnout. Specifically speaking, when teachers have high recognition and identification with the functions and values of the schools they work in, they can take pride in their profession and recognize various 
norms of their school. From this point of view, no matter how tiring and hard their work is, they are not likely to suffer job burnout.

\section{Conclusions and Recommendations}

On the basis of this empirical study, it is found that tertiary EFL teachers' professional identity can significantly predict job burnout. Therefore, teachers' job burnout can be relieved through the improvement of their professional identity, which may be beneficial not only for EFL teachers but also for the teachers in general. On the on hand, school administrators should try to cultivate teachers' occupational values in terms of management system, spirit and culture in the new era. They should help teachers to set the people-oriented philosophy in the process of educating students. Furthermore, school administrators should actively plan and organize a variety of collective activities to enhance teachers' sense of belonging to let teachers to experience relaxing, happy and free atmosphere feel the friendship and warmth of their colleges in the campus. Colleges and universities should attach great importance to teachers' experience at work, and it is necessary to actively organize teachers to participate in the construction of school culture and make teachers feel they are the masters of their school. Only in this way can the teaching quality of the school be better improved. When the schools enjoy high prestige in society, the status of teachers and their sense of belonging to the profession will be simultaneously improved. Last but not least, schools should pay attention to the improvement of EFL teachers' academic qualifications, encourage teachers to actively take part in further studies to improve their theoretical, practical and academic skills. As for teachers, they should face up to their profession, recognize the nature of their profession, have the courage to shoulder the responsibility of education and set up correct professional values. In the process of teaching, they should learn to establish a friendly relationship with students. While guiding and helping students to learn scientific and cultural knowledge, their own professional ability will also be improved. All in all, tertiary EFL teachers' job burnout can be eased through the improvement of their professional identity. Democratic and equal communication system between teachers and school leaders should be established so as to enhance teachers' understanding and recognition of the schools' philosophy and values. In addition, when devoted themselves to work, teachers should also find proper ways to release their pressure to so as to avoid physical and mental exhaustion.

\section{References}

Beijaard, D., Verloop, N., \& Vermunt, J. D. (2000). Teachers' perceptions of professional identity: An exploratory study from a personal knowledge perspective. Teaching and Teacher Education, 16(7), 749-764.

Friedman, I. A., \& Gavish, B. (2003). Teacher burnout: The shattering of the dream for success. Jerusalem: Henrietta Szold Institute.

Hair, J. F., Sarstedt, M., Matthews, L. M., \& Ringle, C. M. (2016). Identifying and treating unobserved heterogeneity with FIMIXPLS: part I-method. European Business Review, 28(1), 63-76.

Hu, B. (2016). On college English teachers' burnout and countermeasures. Master's Thesis, Minnan Normal University.

Kremer, L., \& Hofman, J. E. (1985). Teachers' professional identity and burn-out. Research in Education, 34(1), 89-95.

Lim, H.-W. (2011). Concept maps of Korean EFL student teachers' autobiographical reflections on their professional identity formation. Teaching and Teacher Education, 27(6), 969-981.

Martínez-de-la-Hidalga, Z., \& Villardón-Gallego, L. (2016). Evolution of the concept of the teaching profession in secondary school teacher training. Procedia-Social and Behavioral Sciences, 217, 74-83.

International Journal of Educational Studies

Vol. 3, No.3, pp. 97-105

2020

DOI: $10.53935 / 2641-533 x . v 3 i 3.145$

Corresponding Author: Jing Zhao Funding: This article is supported by Teaching Reform Project 6o6f Hubei Normal University: The Construction of U-S Synergistic Learning Community to Promote the Professional Development of Primary and Secondary School Teachers (Project No:

2019056), and funds for Industry-University Cooperation and Education project of the Ministry of Education (Project No:

201901297002).

Article History:

Received: 21 July 2020

Revised: 26 August 2020

Accepted: 16 September 2020

Published: 19 October 2020

(C) 2020 by the authors: licensee Academic

Publishing Group
Maslach, C., Schaufeli, W. B., \& Leiter, M. P. (2001). Job burnout. Annual Review of Psychology, 52(1), 397-422.

Parker, J. P. (1998). The courage to teach: Exploring the inner landscape of a teacher's life. San Francisco, Calif: Jossey - Bass Publishers.

Wang, S. (2016). The elucidation of "guidelines on college English teaching. Foreign Language World(3), 2-10.

Wang, S., \& Wang, H. (2011). On the state of college English teaching in China and its future development. Foreign Languages in China, 5(4-11), 17

Wei, S. (2005). A view on teachers' professional identity and teachers' professional development. Master's Dissertation. Qufu: Qufu Normal University.

$\mathrm{Wu}$, Z. (2008). New perspectives in researching language teaching: From teaching to the teacher. Foreign Language Education in China (Quarterly), 47-55.

Xu, W., Yang, J., Zhang, S., \& Zhou, K. (2015). From "burnout" to "identity": Analysis of P. E. Teachers' occupation of emotion generative process. Journal of Jilin Sport University, 31(1), 66-69.

Yang, X., \& Yang, X. (2002). An analysis on burnout of teachers. Studies in Foreign Education, 56-60.

Ye, S.-1., \& Sun, Y. (2014). An exploration of the correlation of job burnout to professional identity of college teachers. Health Research, 34(5), 528-530.

Zhang, L. (2019). On the relationship among self-concept, teaching efficacy and job burnout for foreign language teachers in applied universities. Journal of Heihe University. 